\title{
Multiple biomarkers of the cytotoxicity induced by BDE-47 in human embryonic kidney cells
}

\author{
Huifeng $\mathrm{Wu}^{\mathrm{a}}$, Lulu Cao ${ }^{\mathrm{a}, \mathrm{b}}$, Fei $\mathrm{Li}^{\mathrm{a}, *}$, Peiwen Lian $^{\mathrm{c}}$, Jianmin Zhao ${ }^{\mathrm{a}}$ \\ ${ }^{a}$ Key Laboratory of Coastal Zone Environmental Processes and Ecological Remediation, Yantai Institute of Coastal Zone Research (YIC), Chinese Academy of Sciences (CAS), \\ Shandong Provincial Key Laboratory of Coastal Zone Environmental Processes, Yantai, Shandong 264003, PR China \\ ${ }^{\mathrm{b}}$ University of Chinese Academy of Sciences, Beijing 100049, PR China \\ ${ }^{\mathrm{c}}$ Department of Center Laboratory, Yantai Yuhuangding Hospital, Yuhuangdingdong Road 20, Yantai 264000, PR China
}

\section{H I G H L I G H T S}

- BDE-47 induced hormesis effect in HEK293 cells.

- BDE-47 caused cell apoptosis and ROS overproduction in HEK293 cells.

- Bcl-2 family might be the regulator of cell apoptosis in HEK293 cells.

- The disturbance in energy metabolism was induced by BDE-47 exposure.

\section{A R T I C L E I N F O}

\section{Article history:}

Received 8 December 2014

Received in revised form 23 January 2015

Accepted 27 January 2015

Available online 16 February 2015

Handling Editor: Myrto Petreas

\section{Keywords:}

BDE-47

HEK293 cells

Cytotoxicity

Cell apoptosis

ROS

Metabolomics

\begin{abstract}
A B S T R A C T
Polybrominated diphenyl ethers (PBDEs) are widely used as brominated flame-retardants in a variety of industrial products. Among these PBDEs, 2,2',4,4'-tetra-bromodiphenyl ether (BDE-47) is one of the most predominant congeners inducing multiple toxicities, including hepatotoxicity, neurotoxicity, cytotoxicity, genotoxicity, carcinogenecity and immunotoxicity in human body. In this study, the cytotoxicity of BDE-47 in human embryonic kidney cells (HEK293) was investigated by a set of bioassays, including cell proliferation, apoptosis, oxidative stress and metabolic responses as well as gene expressions related to apoptosis. Results showed that BDE-47 induced an inverted U-shaped curve of cell proliferation in HEK293 cells from $10^{-6}$ to $10^{-4} \mathrm{M}$. Cell apoptosis and ROS overproduction were detected at $10^{-5} \mathrm{M}$ of BDE-47 $(p<0.05)$. In addition, the expressions of Bcl-2 family-encoding genes (Bad, $\mathrm{Hrk}$ and Bcl-2) increased significantly in $10^{-4} \mathrm{M}$ group $(p<0.05)$. Metabolic responses indicated that BDE-47 mainly caused disturbance in energy metabolism marked by differentially altered ethanol, glutathione, creatine, aspartate, UDP-glucose and $\mathrm{NAD}^{+}$. The increased lactate/alanine ratios indicated the higher reductive state induced by BDE- 47 in all exposures confirmed by the overproduction of ROS.
\end{abstract}

(c) 2015 Elsevier Ltd. All rights reserved.

\section{Introduction}

As a major class of brominated flame retardants (BFRs), polybrominated diphenyl ethers (PBDEs) are extensively used in many products including rubbers, textiles, polymers and appliances (Alaee et al., 2003; Hites, 2004; Hale et al., 2006). PBDEs can be leached out easily without chemical binding in the products. Because of their persistence and bioaccumulation, PBDEs have been detected in various environmental media, wildlife and human

\footnotetext{
* Corresponding author. Tel.: +86 535 2109189; fax: +865352109000

E-mail address: fli@yic.ac.cn (F. Li).
}

tissues (de Wit, 2002; Schecter et al., 2007; Yogui and Sericano, 2009; Chen and Hale, 2010; de Wit et al., 2010; Bradman et al., 2012; Jakobsson et al., 2012).

The 2,2',4,4'-tetra-bromodiphenyl ether (BDE-47), as a PBDE congener, has been suggested to be the predominant congener in biota and sediments from the Bohai Sea, North China (Jin et al., 2008; Wan et al., 2008; Pan et al., 2010). In addition, BDE-47 is one of five main PBDE congeners (BDE-47, -99, -100, -153 and -154) in human tissues (U.S.EPA, 2010). Thus, there are increasing concerns over BDE-47, especially their adverse effects on environment and human health. 
Some in vitro studies have revealed that BDE-47 could cause toxic effects, such as developmental neurotoxicity, hepatotoxicity, reproduction toxicity, immunotoxicity and endocrine disruption (Lema et al., 2008; Song et al., 2009; Kodavanti et al., 2010; An et al., 2011; Erratico et al., 2011; Zhong et al., 2011; Chen et al., 2012). Apoptosis is a form of self-regulated cell death and a major manifestation of cytotoxicity of contaminants (Kerr et al., 1972). Oxidative stress which could result in cell apoptosis and DNA damage was thought to be the potential mechanism for cytotoxicity of contaminants (Tagliaferri et al., 2010; Pellacani et al., 2012). Until now, there have been substantial evidences indicating that BDE47 could induce cell apoptosis and intracellular oxidative stress in many human cell types (He et al., 2008; Shao et al., 2008; Kawashiro et al., 2009; Yan et al., 2011). He et al. (2008) reported that BDE-47 induced cytotoxicity and genotoxicity in SH-SY5Y cells, including inducing LDH leakage, ROS overproduction, cell apoptosis and DNA damage. An et al. (2011) suggested that BDE47 could induce DNA damage by mediating oxidant/antioxidant balance and the expression of CYP1 family in L02 cells.

In traditional toxicological studies, one or several biomarkers are usually chosen to assess the cytotoxicity of BDE-47 such as apoptosis and ROS production to test for oxidative stress or specific expressed proteins and genes to test for certain toxicities (Crump et al., 2008; Zhong et al., 2011; Wang et al., 2012). However, a single biomarker only indicates a certain toxic effect, which usually lacks a global view on cytotoxicity of BED-47. Thus, it is necessary to use global toxicological biomarkers which can be identified by "omic" approaches. Metabolomics, as an emerging "-omic" approach, focuses on the small molecular weight metabolites that are the end products of metabolism in biological samples, such as tissues and cells (Dondero et al., 2006; Wu et al., 2008). The characterization of the metabolome can provide an insight into the toxicological mechanisms of contaminants on the metabolism of organisms (Ji et al., 2013; Wu et al., 2013).

Although there are few studies on the level of BDE-47 in human kidney, a number of studies have detected BDE-47 in kidneys of other mammals and birds (Chen et al., 2007; Huwe et al., 2008; Liang et al., 2008). In addition, the nephrotoxicity of BDE-47 has been reported in vivo and in vitro models (Emond et al., 2010; Hakk et al., 2010). It is of great importance to investigate the cytotoxicity of contaminants on kidney cell lines. In this study, the toxicological effects of BDE-47 in human embryonic kidney cells (HEK293) were characterized by cell proliferation, apoptosis, and oxidative stress response as well as gene expressions related to apoptosis. Furthermore, NMR-based metabolomic approach was used to detect the metabolic responses in HEK293 cells. These toxicological biomarkers might be used to elucidate the toxicological effects of BDE-47 in HEK293 cells.

\section{Materials and methods}

\subsection{Chemicals and reagents}

Dulbecco's Modified Eagle's Medium (DMEM), Fetal Bovine Serum (FBS), Phosphate Buffered Saline (PBS), Penicillin-Streptomycin Solution and Trypsin were obtained from Hyclone (Logan, Utah, USA). Dimethyl sulfoxide (DMSO) was purchased from MP Biomedicals (Santa Ana, CA, USA). BDE-47 (99.5\%) was purchased from Chem Service (West Chester, PA, USA) and was dissolved in DMSO to prepare stock solution $(0.2 \mathrm{M})$. Cell counting kit-8 (CCK8) was purchased from Dojindo (Kumamoto, Japan). Annexin VFITC/PI detection kit was purchased from Beyotime (Shanghai, China). 2,7-dichlorofluorescein diacetate (DCFH-DA) was purchased from Sigma-Aldrich (China). SYBR Green Real-time PCR Master Mix was purchased from Applied Biosystems (Foster City,
CA, USA). All other reagents used were of analytical grade. All experiments were carried out in at least triplicate.

\subsection{Cell culture and treatment}

The HEK293 cell lines were kindly provided by Dr. Lian Peiwen (Yantai Yuhuangding Hospital of Qingdao University Medical College, China). Cells were cultured in DMEM media supplemented with $10 \%$ FBS and $1 \%$ Penicillin-Streptomycin Solution at $37{ }^{\circ} \mathrm{C}$ in a humidified atmosphere with $5 \% \mathrm{CO}_{2}$. When cells grew to $80 \%$ confluence, the media were discarded, and treated medium containing BDE-47 was added. The control group was cultured in DMEM with $0.1 \%$ DMSO (v/v) only.

\subsection{Cell proliferation assay}

Cells were seeded in 96-well plates at a concentration of $5 \times 10^{4}$ cells per well and left to attach for $24 \mathrm{~h}$. Cells were then treated with different concentrations of BDE-47 (concentration gradient was selected: $10^{-10}, 10^{-9}, 10^{-8}, 10^{-7}, 10^{-6}, 10^{-5}, 10^{-4}$ and $10^{-3} \mathrm{M}$ ) in $100 \mu \mathrm{L}$ of medium for another $24 \mathrm{~h}$. Afterwards, $20 \mu \mathrm{L}$ of CCK-8 reagent was added to each well which was incubated for $4 \mathrm{~h}$ at $37^{\circ} \mathrm{C}$. Then, the absorbance of each well at $450 \mathrm{~nm}$ was measured by a multiskan spectrum microplate spectrophotometer (Infinite M200, TECAN, Männedorf, Switzerland).

\subsection{Assessment of apoptosis and ROS}

According to the results of the cell proliferation assay, three different concentrations of BDE-47 $\left(10^{-6}, 10^{-5}\right.$ and $\left.10^{-4} \mathrm{M}\right)$ were selected to assess apoptosis and ROS. After treated for $24 \mathrm{~h}$, cells were harvested with $0.25 \%$ Trypsin and washed twice with cold PBS. Then cells were centrifuged at $2000 \mathrm{~g}$ for $5 \mathrm{~min}$ at $4{ }^{\circ} \mathrm{C}$ and the supernatant was discarded.

Apoptotic cells were identified and quantified using the Annexin V-FITC/PI detection kit. Approximately $10^{6}$ cells from each group were suspended in $500 \mu \mathrm{L}$ of binding buffer. Cells were incubated with $5 \mu \mathrm{L}$ of Annexin V-FITC at $18{ }^{\circ} \mathrm{C}$ for $5 \mathrm{~min}$ in the dark, and then $5 \mu \mathrm{L}$ of PI was added and incubated for another $5 \mathrm{~min}$ in the dark, the stained cells were immediately analyzed by a flow cytometer (FACSAria, Becton Dickinson, Franklin Lakes, NJ, USA). Data were analyzed with Cell Quest Software (Becton Dickinson, Franklin Lakes, NJ, USA).

The intracellular ROS was determined by fluorescent probe DCFH-DA. Similarly, the $10^{6}$ cells from each group were suspended in $500 \mu \mathrm{L}$ of PBS. Then cells were incubated with $5 \mu \mathrm{L}$ of DCFH-DA at $18^{\circ} \mathrm{C}$ for $1 \mathrm{~h}$ in the dark. The stained cells were immediately analyzed by flow cytometry with the excitation and emission wave length at 488 and $530 \mathrm{~nm}$, respectively. Data were analyzed with Cell Quest Software.

\subsection{Quantitative Real-time PCR of apoptosis-related gene expressions}

In order to investigate the possible mechanisms of apoptosis caused by BDE-47, several apoptosis-related gene expression levels were quantified by quantitative real-time PCR technique. The target genes included $\mathrm{Bax}, \mathrm{Bad}, \mathrm{Bcl}-2$ and $\mathrm{Hrk}$. The constitutive expression gene, HPRT1, was used as endogenous control to normalize mRNA expression levels of the target genes. The primer sequences were listed in Table 1.

After treated with three different concentrations of BDE-47 $\left(10^{-6}, 10^{-5}\right.$ and $\left.10^{-4} \mathrm{M}\right)$ for $24 \mathrm{~h}$, total RNA was isolated in TRIzol reagent from the HEK293 cells following the manufacturer's directions (Invitrogen, Carlsbad, CA, USA). The first-strand cDNA was synthesized according to M-MLV RT Usage information (Promega, Madison, WI, USA). The fluorescent quantitative real-time PCR 
Table 1

RT-PCR primer sequences.

\begin{tabular}{lll}
\hline Gene name & Forward primer $\left(5^{\prime}-3^{\prime}\right)$ & Reverse primer $\left(5^{\prime}-3^{\prime}\right)$ \\
\hline HPRT1 & TGACACTGGCAAAACAATGCA & GGTCCTTTCACCAGCAAGCT \\
Bax & GCGTCCACCAAGAAGCTGAG & ACCACCCTGGTCTTGGATCC \\
Bad & GCTCCACATCCCGAAACT & GGCGGAAAACCCAAAACT \\
Bcl-2 & TGAACCGGCATCTGCACAC & CGTCTTCAGAGACAGCCAGGAG \\
Hrk & CGGCAGGCGGAACTTGTA & GCTCCAGGCGCTGTCTTTAC \\
\hline
\end{tabular}

was performed on an ABI 7500 Real-Time Detection System to investigate the mRNA expressions (Applied Biosystems, Foster City, CA, USA). The PCR amplifications were carried out in triplicate in a total volume of $25.0 \mu \mathrm{L}$ containing $12.5 \mu \mathrm{L}$ of $2 \times$ SYBR Green Master Mix, $4.0 \mu \mathrm{L}$ of $1: 20$ diluted cDNA, $1.0 \mu \mathrm{L}$ of each primer and $6.5 \mu \mathrm{L}$ of PCR-grade water. The PCR program was $94^{\circ} \mathrm{C}$ for $7 \mathrm{~min}$, followed by 40 cycles of $10 \mathrm{~s}$ at $95^{\circ} \mathrm{C}, 30 \mathrm{~s}$ at $60^{\circ} \mathrm{C}$. After the PCR program, data were analyzed with the ABI 7500 SDS software (Applied BioSystems, Foster City, CA, USA). The expression levels of five apoptosis-related genes were analyzed by the $2^{-\Delta \Delta C_{T}}$ method as previously described (Livak and Schmittgen, 2001; Duarte and Jones, 2007).

\subsection{Preparation of cell samples for NMR}

After treated with three different concentrations of BDE-47 $\left(10^{-6}, 10^{-5}\right.$ and $\left.10^{-4} \mathrm{M}\right)$ for $24 \mathrm{~h}$, cells were harvested with $0.25 \%$ Trypsin and washed twice with cold PBS. After centrifugation at $2000 \mathrm{~g}$ for $5 \mathrm{~min}$ at $4{ }^{\circ} \mathrm{C}$, the supernatant was discarded. Then, cells were immediately flash-frozen in liquid nitrogen. Frozen cell were lyophilized and weighed before metabolite extraction. Each group contained eight biological replicates.

\subsection{Metabolite extraction}

Polar metabolites in the cells were extracted by the modified extraction protocol as described previously (Wu et al., 2008). Briefly, the dried cell pellet (ca. $10 \mathrm{mg}$ dry weight) was homogenized and extracted in $40 \mathrm{~mL} \mathrm{~g}^{-1}$ of methanol, $52.5 \mathrm{~mL} \mathrm{~g}^{-1}$ of water and $20 \mathrm{~mL} \mathrm{~g}^{-1}$ of chloroform. The methanol/water layer with polar metabolites was transferred to a glass vial and dried in a centrifugal concentrator. The extracts were subsequently re-suspended in $600 \mu \mathrm{L}$ of phosphate buffer $\left(100 \mathrm{mM} \mathrm{Na} \mathrm{NPO}_{4}\right.$ and $\mathrm{NaH}_{2} \mathrm{PO}_{4}$, including $0.5 \mathrm{mM}$ TSP, $\mathrm{pH} 7.0$ ) in $\mathrm{D}_{2} \mathrm{O}$. The mixture was vortexed and then centrifuged at $3000 \mathrm{~g}$ for $5 \mathrm{~min}$ at $4{ }^{\circ} \mathrm{C}$. The supernatant $(550 \mu \mathrm{L})$ was then pipetted into a $5 \mathrm{~mm}$ NMR tube prior to NMR analysis.

\section{8. ${ }^{1} \mathrm{H}$ NMR spectroscopy}

Metabolite extracts of HEK293 cells were analyzed on a Bruker AV 500 NMR spectrometer performed at $500.18 \mathrm{MHz}$ (at $25^{\circ} \mathrm{C}$ ) as described previously (Liu et al., 2011). One-dimensional (1-D) ${ }^{1} \mathrm{H}$ NMR spectra were obtained using a $11.9 \mu$ s pulse, $6009.6 \mathrm{~Hz}$ spectral width, mixing time $0.1 \mathrm{~s}$, and $3.0 \mathrm{~s}$ relaxation delay with standard 1D NOESY pulse sequence, with 256 transients collected into 16384 data points. Datasets were zero-filled to 32768 points, and exponential line-broadenings of $0.3 \mathrm{~Hz}$ were applied before Fourier transformation. All ${ }^{1} \mathrm{H}$ NMR spectra were phased, baseline-corrected and calibrated (internal reference: 2,2,3,3-d(4)-3-(trimethylsilyl) propionic acid sodium salt (TSP) at $0.0 \mathrm{ppm}$ ) manually using TopSpin (version 2.1, Bruker).

\subsection{Spectral pre-processing and pattern recognition analysis}

All one dimensional ${ }^{1} \mathrm{H}$ NMR spectra were converted into a data matrix using the custom-written ProMetab software in Matlab version 7.1 (The MathsWorks, Natick, MA, USA) (Zhang et al., 2011a, b). Each spectrum was segmented into bins with a width of $0.005 \mathrm{ppm}$ between 0.2 and $10.0 \mathrm{ppm}$. The bins of residual water peak between 4.70 and $5.20 \mathrm{ppm}$ were excluded from all the NMR spectra. The total spectral area of the remaining bins was normalized to unity to facilitate the comparison between the spectra. All the NMR spectra were generalized log transformed (glog) with a transformation parameter $\lambda=2.0 \times 10^{-9}$ to stabilize the variance across the spectral bins and to increase the weightings of the less intense peaks (Parsons et al., 2007). Before pattern recognition analysis, the data sets were mean-centered.

Pattern recognition analysis was performed with the software SIMCA-P ${ }^{+}$(V11.0, Umetric, Sweden). The unsupervised pattern recognition method, principal component analysis (PCA) was used to reduce the dimensionality of the data and summarize the similarities and differences between multiple NMR spectra (Xu, 2004). One-way analysis of variance (ANOVA) was conducted on the PC scores from each group to test the statistical significance $(p<0.05)$ of separations. Furthermore, the supervised multivariate data analysis methods, partial least squares discriminant analysis (PLS-DA) and orthogonal projection to latent structure with discriminant analysis (O-PLS-DA), were sequentially carried out to uncover and extract the statistically significant metabolite variations related to BDE-47 exposures, as described previously (Feng et al., 2013). Metabolites were identified following the tabulated chemical shifts (Fan, 1996) and by using the software, Chenomx (Evaluation Version, Chenomx Inc., Edmonton, Alberta, Canada).

\subsection{Statistical analysis}

Statistical analysis of data was performed by one-way analysis of variance (one-way ANOVA) using SPSS 16.0 statistical software. The $p$ values less than 0.05 were considered statistically significant.

\section{Results and discussion}

\subsection{Cytotoxicity responses of BDE-47 in HEK293 cells}

CCK-8 was used to evaluate the cell proliferation ability. As shown in Fig. 1, after $24 \mathrm{~h}$ treatment, $10^{-6}$ and $10^{-5} \mathrm{M}$ BDE-47 exposure showed a significant promotion of cell proliferation $(p<0.01)$, while BDE-47 at $10^{-4}$ and $5 \times 10^{-4} \mathrm{M}$ could significantly inhibit HEK293 cell proliferation $(p<0.01)$. Based on the results, the concentration range of $10^{-6}-10^{-4} \mathrm{M} \mathrm{BDE}-47$ was chosen for the following experiments in which an inverted U-shaped curve of cell proliferation was detected.

The HEK293 cells were treated with three concentrations of BDE-47 $\left(10^{-6}, 10^{-5}\right.$ and $\left.10^{-4} \mathrm{M}\right)$ for $24 \mathrm{~h}$, then apoptosis and ROS were measured by flow cytometry. Compared with the DMSO control, the treatment with BDE-47 at $10^{-5}$ and $10^{-4} \mathrm{M}$ significantly increased $(p<0.05)$ apoptosis ratio (Fig. 2A). As shown in Fig. 2B, a significant increase of ROS production was observed in HEK293 cells with $10^{-5} \mathrm{M}$ BDE-47 treatment compared with that in control group ( $p<0.01$ ), while ROS level in the $10^{-4} \mathrm{M}$ group decreased significantly $(p<0.01)$.

In this study, the cell proliferation assay revealed that BDE-47 induced hormesis effect in HEK293 cells exposed to the concentration range of $10^{-6}-10^{-4} \mathrm{M}(p<0.01)$. Similar results were observed in human neuroblastoma cells (He et al., 2008). Thus, the cytotoxicity and its relevant mechanism of BDE-47 in this concentration range should be focused on. Further analysis on cell apoptosis 


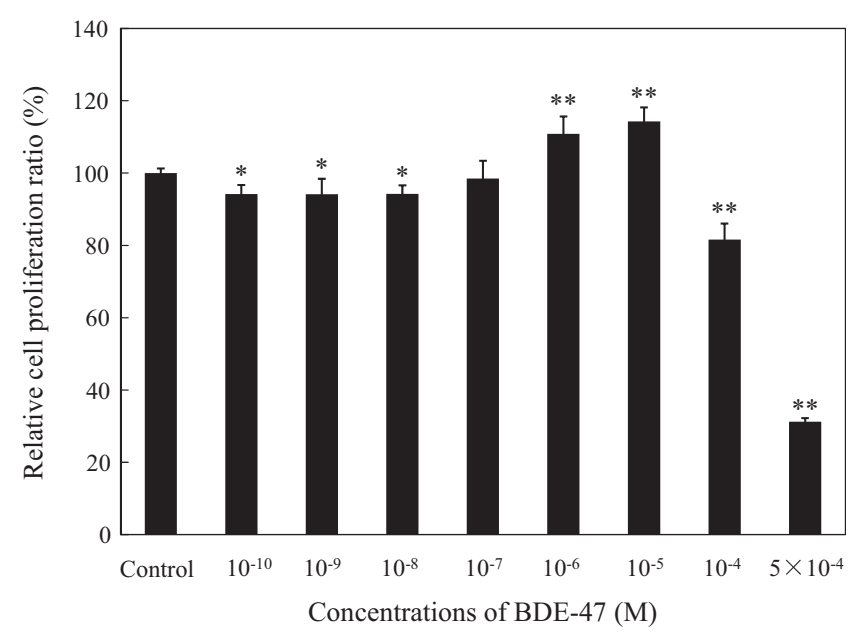

Fig. 1. Effect of BDE-47 on HEK293 cells proliferation. Cells were incubated in the absence (DMSO, control) or presence of BDE-47 $\left(10^{-10}, 10^{-9}, 10^{-8}, 10^{-7}, 10^{-6}, 10^{-5}\right.$, $10^{-4}$ and $5 \times 10^{-4} \mathrm{M}$ ) for $24 \mathrm{~h}$. Cell proliferation is expressed as percentages of the value for the control group, which is set at $100 \%$. Data are presented as mean \pm standard deviation of triplicate experiments. The levels of significances are set at ${ }^{*} p<0.05,{ }^{* *} p<0.01$ vs. control.

showed that BDE-47 could cause cell apoptosis at $10^{-5}$ and $10^{-4} \mathrm{M}$ $(p<0.05)$, so that apoptosis was postulated to be one of the important reasons for the decrease of cell proliferation.

ROS can cause cytochrome $C$ release from mitochondria, which induces cell apoptosis (Zorov et al., 2006). A significant increase of ROS production was observed in the $10^{-5} \mathrm{M}$ group $(p<0.01)$, which was in accordance with the result of apoptosis. However, it is interesting that ROS level in the $10^{-4} \mathrm{M}$ BDE-47-exposed group decreased significantly $(p<0.01)$. The dead cell ratio was accounted for $7.3 \%$, which was larger than other groups. This might cause ROS not be detected.

Bcl-2 family is an important regulator of cell apoptosis (Petros et al., 2004). In the present study, four Bcl-2 family-encoding genes were chosen, including $\mathrm{Bcl}-2$ (which is anti-apoptotic), Bax, Bad and Hrk (which are pro-apoptotic). As shown in Table 2, the expressions of Bad, Hrk and $\mathrm{Bcl}-2$ increased significantly in $10^{-4} \mathrm{M}$ group $(p<0.05)$. It was suggested that Bad and Hrk could dimerize with $B c l-2$, so that Bax was released to induce apoptosis (Yang et al., 1995; Inohara et al., 1997). Cell apoptosis might be a result of combined action of Bad, Hrk and Bcl-2 in this study.
Table 2

Effect of BDE-47 on apoptosis-related gene expression levels in HEK293 cells.

\begin{tabular}{lllll}
\hline Group & Bax & Bad & Bcl-2 & Hrk \\
\hline Control & $1.13 \pm 0.20$ & $1.00 \pm 0.03$ & $1.01 \pm 0.04$ & $1.01 \pm 0.06$ \\
$10^{-6} \mathrm{M}$ & $1.00 \pm 0.17$ & $1.06 \pm 0.06$ & $1.42 \pm 0.34$ & $1.21 \pm 0.07$ \\
$10^{-5} \mathrm{M}$ & $1.15 \pm 0.12$ & $0.98 \pm 0.03$ & $1.52 \pm 0.25$ & $1.25 \pm 0.05$ \\
$10^{-4} \mathrm{M}$ & $1.37 \pm 0.26$ & $1.61 \pm 0.01^{*}$ & $2.34 \pm 0.38^{*}$ & $2.26 \pm 0.08^{*}$ \\
\hline
\end{tabular}

$p<0.05$ is considered significant between control and BDE-47 treatment.

\subsection{Metabolic responses of BDE-47 in HEK293 cells}

As a well-established system biology technique, metabolomics has been widely used to elucidate chemical-induced toxicological effects and the underlying mechanisms (Liu et al., 2011; Williams et al., 2011). In this work, we performed NMR-based metabolomics to elucidate the dose responses of BDE-47 $\left(10^{-6}, 10^{-5}\right.$ and $10^{-4} \mathrm{M}$ ) to HEK293 cell lines.

Fig. 3 indicated the representative ${ }^{1} \mathrm{H}$ NMR spectra of cell extracts from control and BDE-47-exposed groups. The identified metabolites in the ${ }^{1} \mathrm{H}$ NMR spectra were labeled in Fig. 3. Different classes of metabolites were identified including amino acids (isoleucine, leucine, valine, alanine, threonine, aspartate, glutamate, glycine, etc.), organic acids (lactate, succinate, creatine and fumarate), organic osmolytes (dimethylamine, dimethylglycine and myo-inositol) and energy storage compounds (ATP and uridine diphosphate glucose (UDP-glucose)).

PCA was conducted on all the NMR spectral datasets with significant $(p<0.05)$ separations between control and BDE-47exposed groups along PC1 axis and/or PC2 axis (Fig. 4), suggesting that these BDE-47 exposures induced significant metabolic differences in HEK293 cells. In details, the highest concentration $\left(10^{-4} \mathrm{M}\right)$ of BDE-47-treated group was significantly separated from control and the two lower dosage $\left(10^{-6}\right.$ and $\left.10^{-5} \mathrm{M}\right)$ groups along PC1 axis in the scores plot (Fig. 4). However, there was no significant separation between the two lower dosage $\left(10^{-6}\right.$ and $\left.10^{-5} \mathrm{M}\right)$ groups along PC1 axis but along PC2 axis, which implied there were both similar and differential effects of BDE-47 at $10^{-6}$ and $10^{-5} \mathrm{M}$ to HEK293 cells. These findings confirmed the doseresponsive effects induced by $\mathrm{BDE}-47$ at these selected concentrations $\left(10^{-6}, 10^{-5}\right.$ and $\left.10^{-4} \mathrm{M}\right)$.

To detect the metabolic response to BDE-47 exposures, the orthogonal projection to latent structure with discriminant analysis (O-PLS-DA) was performed on the corresponding NMR data from the pair-wise HEK293 cell groups (control vs. each BDE-47

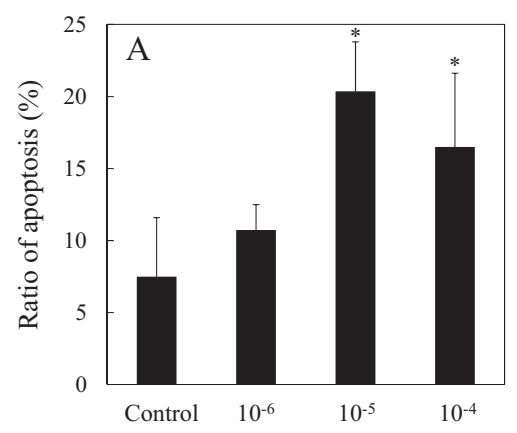

Concentrations of BDE-47 (M)

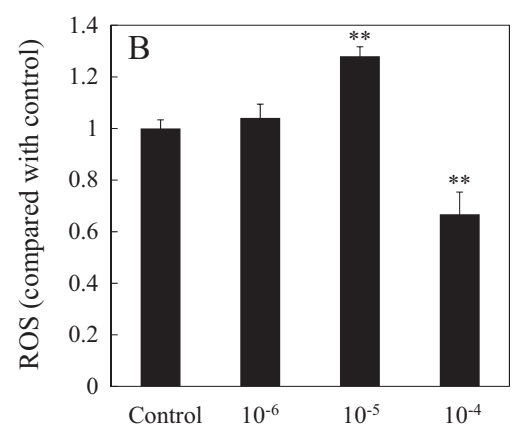

Concentrations of BDE-47 (M)

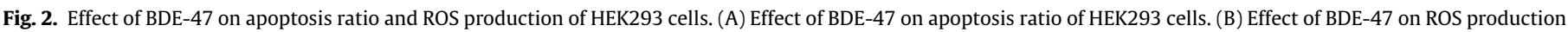

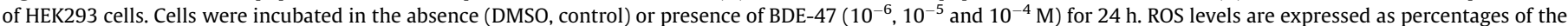

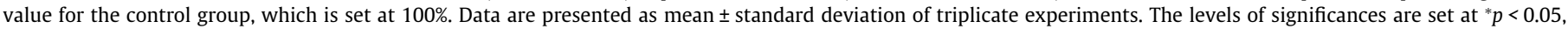
${ }^{* *} p<0.01$ vs. control. 


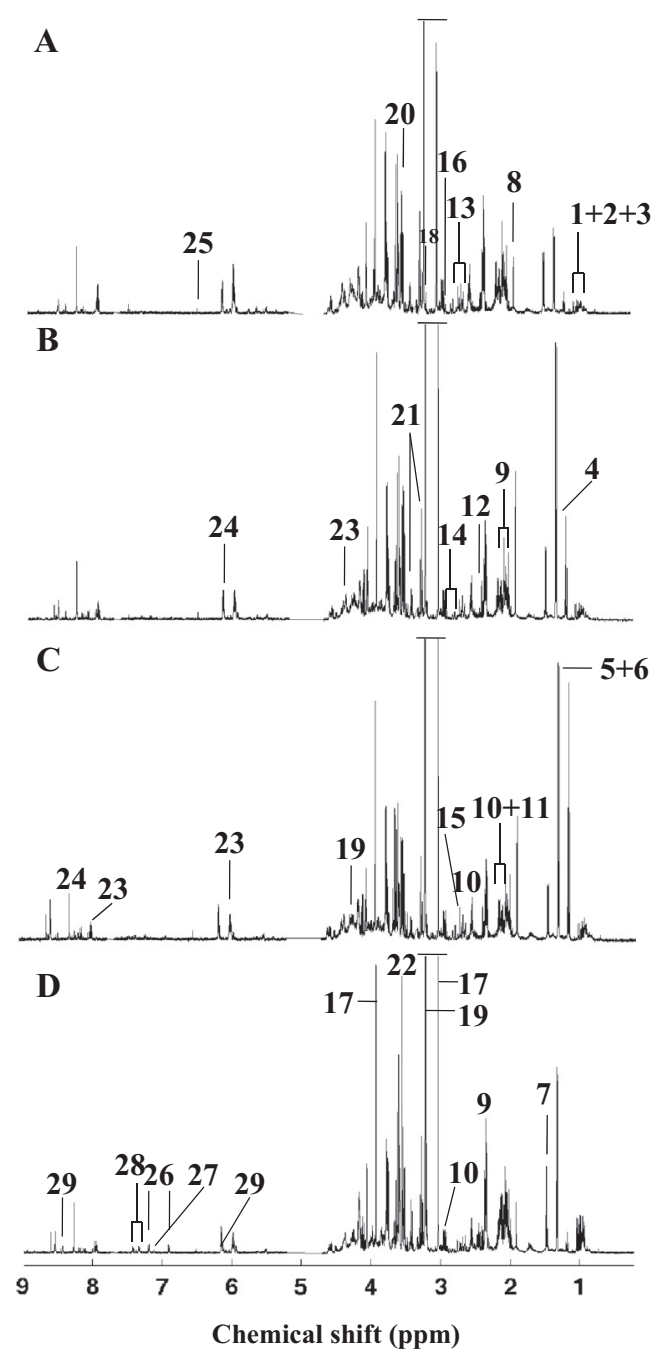

Fig. 3. Representative 1-dimensional $500 \mathrm{MHz}{ }^{1} \mathrm{H}$ NMR spectra of HEK293 extracts from (A) control, (B) $10^{-6}$ (C) $10^{-5}$ and (D) $10^{-4} \mathrm{M}$ BDE-47-treated groups. Keys: (1) isoleucine, (2) leucine, (3) valine, (4) ethanol, (5) threonine, (6) lactate, (7) alanine, (8) acetate, (9) glutamate, (10) glutathione, (11) glutamine, (12) succinate, (13) aspartate, (14) asparagine, (15) dimethylamine, (16) dimethylglycine, (17) creatine, (18) choline, (19) phosphocholine, (20) myo-inositol, (21) taurine, (22) glycine, (23) UDP-glucose, (24) ATP, (25) fumarate, (26) tyrosine, (27) histidine, (28) phenylalanine and (29) $\mathrm{NAD}^{+}$.

treatment). The O-PLS-DA scores and loadings plots derived from the NMR data of pair-wise groups were shown in Fig. 5. All OPLS-DA resulted in obvious separation between control and each BDE-47 treatment with reliable $Q^{2}$ values $(>0.75)$ revealing the significant metabolic responses of BDE-47 exposures (Fig. 5A, C and E). The significant metabolites responsible for the separations were shown in the corresponding loadings plots (Fig. 5B, D and F). The low concentration $\left(10^{-6} \mathrm{M}\right)$ of BDE-47 increased the levels of valine, ethanol, lactate and alanine, and decreased the levels of glutathione, aspartate, creatine, UDP-glucose and NAD ${ }^{+}$(Fig. 5B). As shown in the loadings plot (Fig. 5D), the medium concentration $\left(10^{-5} \mathrm{M}\right)$ of BDE-47 induced some similar metabolic responses, including the increased ethanol and decreased glutathione, aspartate, creatine, UDP-glucose and $\mathrm{NAD}^{+}$, compared with those metabolic responses from the low dosage group. However, the depleted myo-inositol was uniquely observed in the medium concentration $\left(10^{-5} \mathrm{M}\right)$ of BDE-47-treated cell samples. For the high concentration $\left(10^{-4} \mathrm{M}\right)$ of BDE-47 exposure, glutathione, aspartate, creatine, UDP-glucose and $\mathrm{NAD}^{+}$were significantly decreased, which was similarly observed in both low and medium concentrations $\left(10^{-6}\right.$

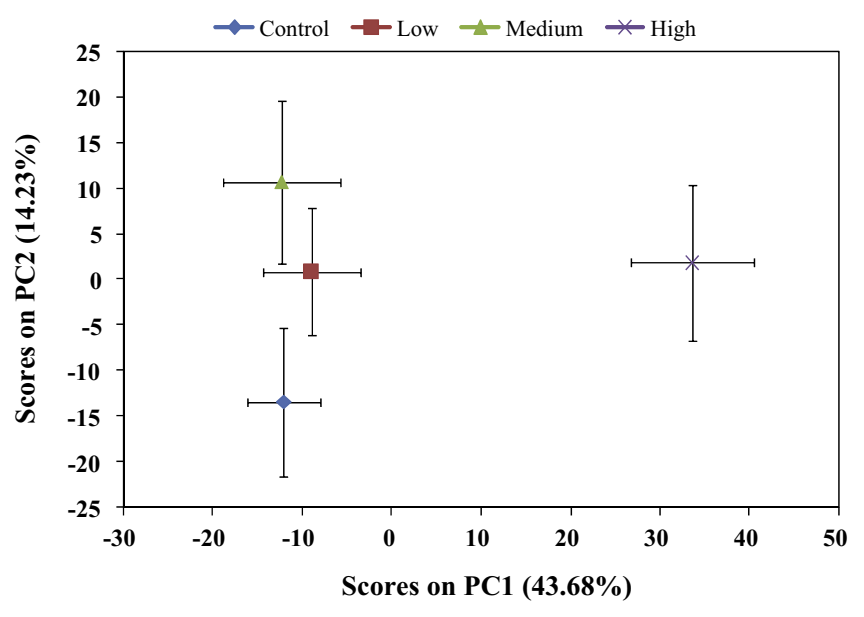

Fig. 4. Mean principal component analysis (PCA) scores plot of PC1 versus PC2 for ${ }^{1} \mathrm{H}$ NMR spectra of HEK293 cell extracts from control, $10^{-6}, 10^{-5}$ and $10^{-4} \mathrm{M}$ BDE47-treated groups. The classes are presented as mean \pm standard deviation (as associated standard error) of PC scores for each group.

and $10^{-5} \mathrm{M}$ ). However, the branched chain amino acids (BCAAs), glutamate, glutamine, dimethylamine, phosphocholine, glycine, tyrosine and phenylalanine were uniquely increased in the high concentration of BDE-47-treated samples.

Ethanol is a production of the anaerobic cell respiration process, and the increased ethanol in the low and medium BDE-47 dosage $\left(10^{-6}\right.$ and $\left.10^{-5} \mathrm{M}\right)$ groups might mean that these two concentrations of BDE-47 caused a reduction in alcohol dehydrogenase activity in the glycolysis process (Wu et al., 2006). Glutathione is an important antioxidant preventing damage to important cellular components caused by reactive oxygen species such as free radicals and peroxides. The decreased glutathione probably meant the increased production of reactive oxygen species induced by BDE-47 exposures and subsequent excessive consumption of glutathione in HEK293 cells. Creatine is a nitrogenous organic acid naturally occurring in vertebrates and supplying energy to all cells by increasing the formation of adenosine triphosphate (ATP). The depletion of creatine could suggest the enhanced energy demand induced by these three concentrations of BDE-47. Aspartate is a metabolite involved in gluconeogenesis that is a metabolic pathway resulting in the generation of glucose from non-carbohydrate carbon substrates such as pyruvate, lactate, glycerol, and glucogenic amino acids. UDP-glucose is involved in nucleotide sugars metabolism as an activated form of glucose and catalyzed by enzymes called glucosyltransferases (Rademacher et al., 1988). In addition, it is a precursor of glycogen and can be converted into UDP-galactose and UDP-glucuronic acid, which can then be used as substrates by the enzymes that make polysaccharides containing galactose and glucuronic acid. Therefore, the decreased aspartate and UDP-glucose meant the disturbance in energy metabolism caused by these three BDE-47 exposures, combined with the decreased creatine in HEK293 cells. NAD ${ }^{+}$is the oxidizing form of nicotinamide adenine dinucleotide (NAD) that is involved in redox reactions catalyzed by oxidoreductases. Here, reduced compounds such as glucose and fatty acids are oxidized, thereby releasing energy. This energy is transferred to $\mathrm{NAD}^{+}$by reduction to $\mathrm{NADH}$, as part of beta oxidation, glycolysis, and the citric acid cycle. Clearly, the depletion of $\mathrm{NAD}^{+}$also implied the disturbance in energy metabolism induced by all the three BDE-47 exposures.

In the low concentration $\left(10^{-6} \mathrm{M}\right)$ of BDE-47-treated group, the increase of lactate indicated the reduced utilization of pyruvate in citric acid cycle and an increase in anaerobic cell respiration. Phosphocholine is made in a reaction catalyzed by choline kinase converting ATP and choline into phosphocholine and ADP. The 

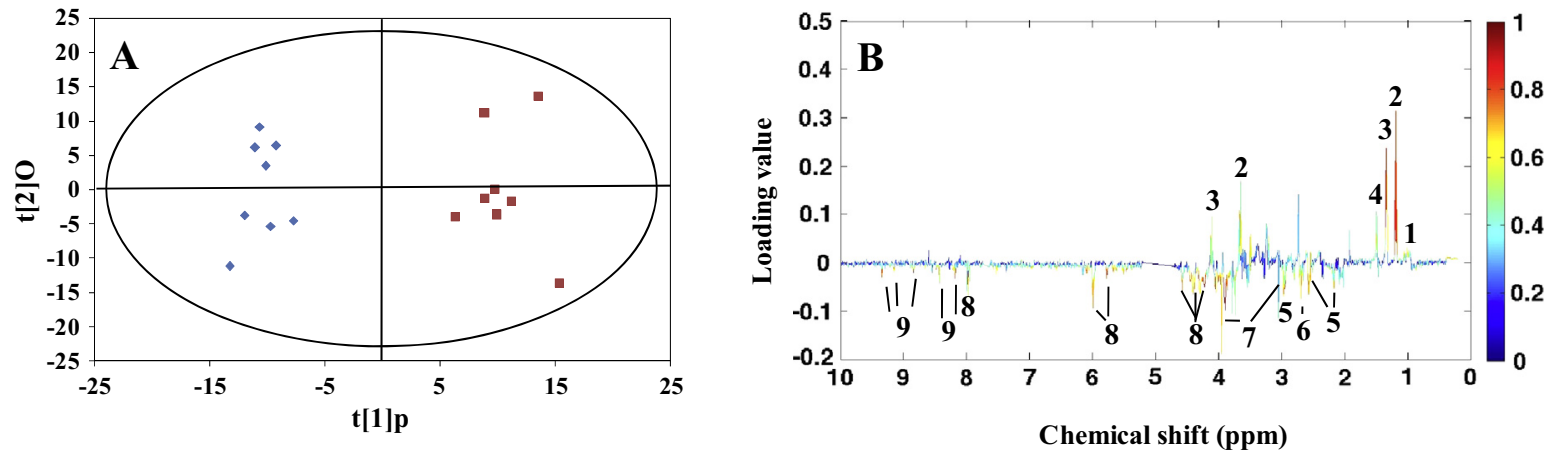

$R^{2} X=41.4 \%, Q^{2}=0.858$
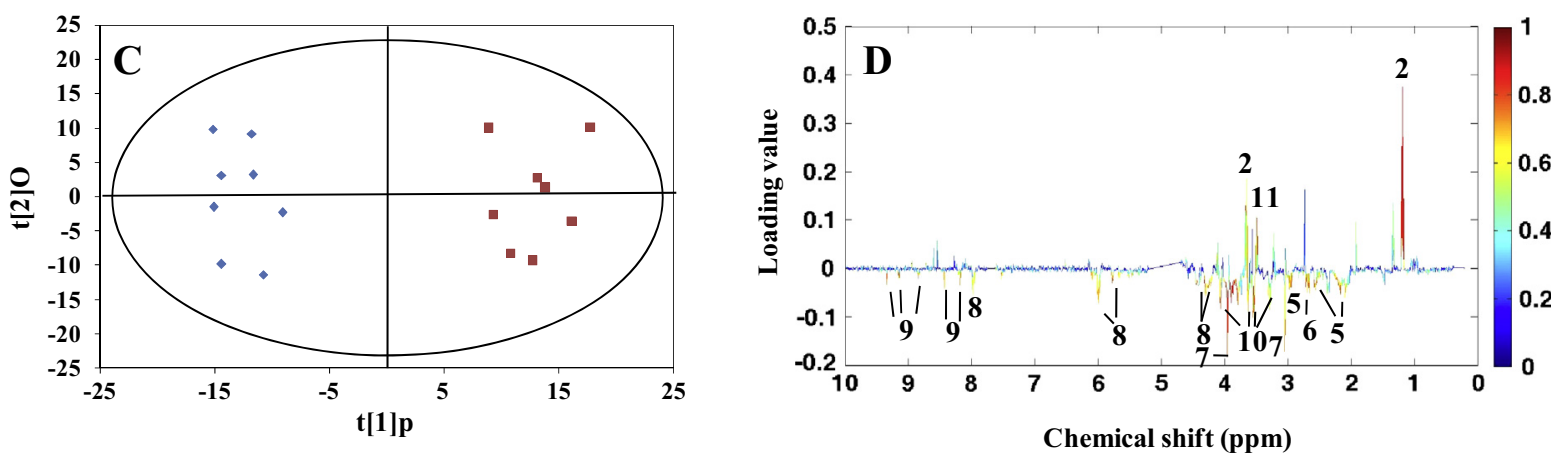

$R^{2} X=41.6 \%, Q^{2}=0.787$
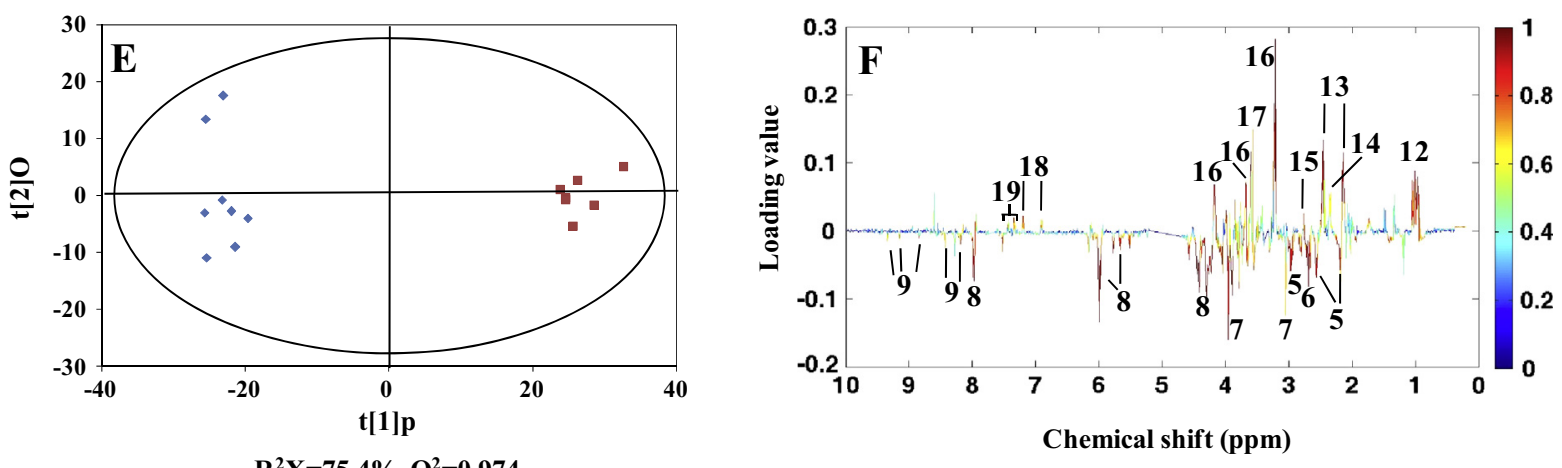

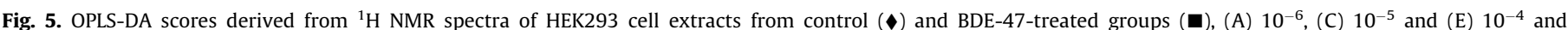

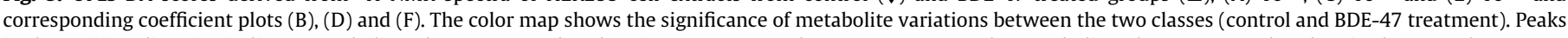

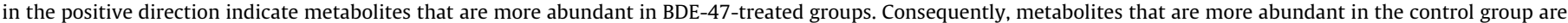

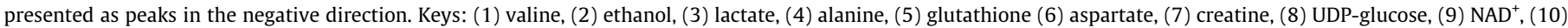

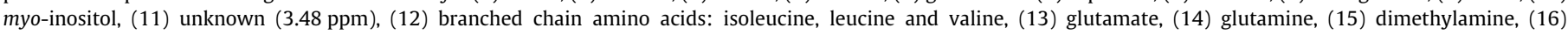

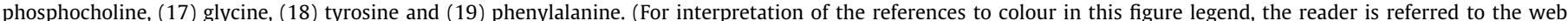
version of this article.)

elevation of phosphocholine implied the enhanced conversion of ATP and choline to phosphocholine and ADP in the high concentration $\left(10^{-4} \mathrm{M}\right) \mathrm{BDE}-47$-treated samples. Some amino acids were significantly increased in both low and high concentrations of $\left(10^{-6}\right.$ and $10^{-4} \mathrm{M}$ ), which indicated a stimulation of protein catabolism in response to BDE-47 exposure, which was related to the cellular membrane permeability (Mingeotleclercq et al., 1995). Previous studies reported that the ratio of lactate/alanine can be served to be an indicative of cellular redox state (Oliveira et al., 2011; Rato et al., 2012). A lower ratio of lactate/alanine means the lower reductive/higher oxidative state for the cells. In our study, the increased lactate/alanine ratios were observed in all BDE-47-treated groups, which indicated the higher reductive state induced by BDE-47 in HEK293 cells. Interestingly, the ratios of lactate/alanine in three BDE-47 treatments were highly consistent with the productions of ROS, which suggested that BDE-47-induced ROS caused the higher reductive state in HEK 293 cells. Myo-inositol is related to cellular membrane permeability, therefore the depletion of myo-inositol possibly implied a stress-response of cellular membrane in HEK293 cells to the exposure of the medium concentration $\left(10^{-5} \mathrm{M}\right)$ of BDE-47 (Griffin et al., 2003). However, myo-inositol was not altered in both low and high concentrations of BDE47 treatment, which could imply the hormesis effect of BDE-47 to HEK293 cells.

\section{Conclusions}

In this study, the cytotoxicity of BDE-47 in HEK293 cells was studied by an integrated traditional toxicological and metabolomic approach. It was suggested that BDE-47 could cause the hormesis effect in HEK293 cells. Cell apoptosis and ROS overproduction were induced by BDE- 47 and the Bcl-2 family was regarded as the regu- 
lator of cell apoptosis in HEK293 cells. The metabolic response indicated that the disturbance in energy metabolism, stimulation of protein catabolism and stress-response of cellular membrane were caused by BDE-47 exposures in HEK293 cells.

\section{Acknowledgments}

This research was supported by the Strategic Priority Research Program of the Chinese Academy of Sciences (XDA11020405), the Key Research Program of the Chinese Academy of Sciences (Grant No. KZZD-EW-14), the National Natural Science Foundation of China (21107136) and the International Foundation for Science (F/5230-1).

\section{References}

Alaee, M., Arias, P., Sjodin, A., Bergman, A., 2003. An overview of commercially used brominated flame retardants, their applications, their use patterns in different countries/regions and possible modes of release. Environ. Int. 29, 683-689.

An, J., Yin, L., Shang, Y., Zhong, Y., Zhang, X., Wu, M., Yu, Z., Sheng, G., Fu, J., Huang, Y., 2011. The combined effects of BDE47 and BaP on oxidatively generated DNA damage in L02 cells and the possible molecular mechanism. Mutat. Res-Gen. Tox. En. 721, 192-198.

Bradman, A., Castorina, R., Sjodin, A., Fenster, L., Jones, R.S., Harley, K.G., Chevrier, J., Holland, N.T., Eskenazi, B., 2012. Factors associated with serum polybrominated diphenyl ether (PBDE) levels among school-age children in the CHAMACOS cohort. Environ. Sci. Technol. 46, 7373-7381.

Chen, D., Hale, R.C., 2010. A global review of polybrominated diphenyl ether flame retardant contamination in birds. Environ. Int. 36, 800-811.

Chen, D., Mai, B., Song, J., Sun, Q., Luo, Y., Luo, X., Zeng, E., Hale, R.C., 2007. Polybrominated diphenyl ethers in birds of prey from Northern China. Environ. Sci. Technol. 41, 1828-1833.

Chen, X., Huang, C., Wang, X., Chen, J., Bai, C., Chen, Y., Chen, X., Dong, Q., Yang, D., 2012. BDE-47 disrupts axonal growth and motor behavior in developing zebrafish. Aquat. Toxicol. 120, 35-44.

Crump, D., Jagla, M.M., Chiu, S., Kennedy, S.W., 2008. Detection of PBDE effects on mRNA expression in chicken (Gallus domesticus) neuronal cells using real-time RT-PCR and a new differential display method. Toxicol. in Vitro 22, 1337-1343.

de Wit, C.A., 2002. An overview of brominated flame retardants in the environment. Chemosphere 46, 583-624.

de Wit, C.A., Herzke, D., Vorkamp, K., 2010. Brominated flame retardants in the Arctic environment-trends and new candidates. Sci. Total Environ. 408, 28852918.

Dondero, F., Dagnino, A., Jonsson, H., Capri, F., Gastaldi, L., Viarengo, A., 2006. Assessing the occurrence of a stress syndrome in mussels (Mytilus edulis) using a combined biomarker/gene expression approach. Aquat. Toxicol. 78, S13-S24.

Duarte, T.L., Jones, G.D.D., 2007. Vitamin C modulation of $\mathrm{H}_{2} \mathrm{O}_{2}$-induced damage and iron homeostasis in human cells. Free Radical Bio. Med. 43, 1165-1175.

Emond, C., Raymer, J.H., Studabaker, W.B., Garner, C.E., Birnbaum, L.S., 2010. A physiologically based pharmacokinetic model for developmental exposure to BDE-47 in rats. Toxicol. Appl. Pharm. 242, 290-298.

Erratico, C.A., Moffatt, S.C., Bandiera, S.M., 2011. Comparative oxidative metabolism of BDE-47 and BDE-99 by rat hepatic microsomes. Toxicol. Sci. 123, 37-47.

Fan, W.M.T., 1996. Metabolite profiling by one- and two-dimensional NMR analysis of complex mixtures. Prog. Nucl. Mag. Res. Sp. 28, 161-219.

Feng, J., Li, J., Wu, H., Chen, Z., 2013. Metabolic responses of HeLa cells to silica nanoparticles by NMR-based metabolomic analyses. Metabolomics 9, 874-886.

Griffin, J.L., Pole, J.C.M., Nicholson, J.K., Carmichael, P.L., 2003. Cellular environment of metabolites and a metabonomic study of tamoxifen in endometrial cells using gradient high resolution magic angle spinning ${ }^{1} \mathrm{H}$ NMR spectroscopy. BBA-Gen. Subjects 1619, 151-158.

Hakk, H., Huwe, J.K., Murphy, K., Rutherford, D., 2010. Metabolism of 2,2',4,4'Tetrabromodiphenyl Ether (BDE-47) in Chickens. J. Agr. Food Chem. 58, 87578762.

Hale, R.C., La Guardia, M.J., Harvey, E., Gaylor, M.O., Mainor, T.M., 2006. Brominated flame retardant concentrations and trends in abiotic media. Chemosphere 64, 181-186.

He, W., He, P., Wang, A., Xia, T., Xu, B., Chen, X., 2008. Effects of PBDE-47 on cytotoxicity and genotoxicity in human neuroblastoma cells in vitro. Mutat. Res-Gen. Tox. En. 649, 62-70.

Hites, R.A., 2004. Polybrominated diphenyl ethers in the environment and in people: a meta-analysis of concentrations. Environ. Sci. Technol. 38, 945-956.

Huwe, J.K., Hakk, H., Birnbaum, L.S., 2008. Tissue distribution of polybrominated diphenyl ethers in male rats and implications for biomonitoring. Environ. Sci. Technol. 42, 7018-7024.

Inohara, N., Ding, L.Y., Chen, S., Nunez, G., 1997. Harakiri, a novel regulator of cell death, encodes a protein that activates apoptosis and interacts selectively with survival-promoting proteins Bcl-2 and Bcl-X $\mathrm{X}_{\mathrm{L}}$. Embo J. 16, 1686-1694.
Jakobsson, K., Fang, J., Athanasiadou, M., Rignell-Hydbom, A., Bergman, A., 2012. Polybrominated diphenyl ethers in maternal serum, umbilical cord serum, colostrum and mature breast milk. Insights from a pilot study and the literature. Environ. Int. 47, 121-130.

Ji, C., Wu, H., Wei, L., Zhao, J., Lu, H., Yu, J. 2013, Proteomic and metabolomic analysis of earthworm Eisenia fetida exposed to different concentrations of 2,2',4,4'-tetrabromodiphenyl ether. J. Proteomics 91, 405-416.

Jin, J., Liu, W., Wang, Y., Tang, X., 2008. Levels and distribution of polybrominated diphenyl ethers in plant, shellfish and sediment samples from Laizhou Bay in China. Chemosphere 71, 1043-1050.

Kawashiro, Y., Fukata, H., Sato, K., Aburatani, H., Takigami, H., Mori, C., 2009 Polybrominated diphenyl ethers cause oxidative stress in human umbilical vein endothelial cells. Hum. Exp. Toxicol. 28, 703-713.

Kerr, J.F.R., Wyllie, A.H., Currie, A.R., 1972. Apoptosis: a basic biological phenomenon with wide-ranging implications in tissue kinetics. Brit. J. Cancer 26, 239-257.

Kodavanti, P.R.S., Coburn, C.G., Moser, V.C., MacPhail, R.C., Fenton, S.E., Stoker, T.E. Rayner, J.L., Kannan, K., Birnbaum, L.S., 2010. Developmental exposure to a commercial PBDE mixture, DE-71: neurobehavioral, hormonal, and reproductive effects. Toxicol. Sci. 116, 297-312.

Lema, S.C., Dickey, J.T., Schultz, I.R., Swanson, P., 2008. Dietary exposure to 2,2',4,4' tetrabromodiphenyl ether (PBDE-47) alters thyroid status and thyroid hormone-regulated gene transcription in the pituitary and brain. Environ. Health Perspect. 116, 1694-1699.

Liang, S., Zhao, Q., Qin, Z., Zhao, X., Yang, Z., Xu, X., 2008. Levels and distribution of polybrominated diphenyl ethers in various tissues of foraging hens from an electronic waste recycling area in South China. Environ. Toxicol. Chem. 27, 1279-1283.

Liu, X., Zhang, L., You, L., Cong, M., Zhao, J., Wu, H., Li, C., Liu, D., Yu, J., 2011 Toxicological responses to acute mercury exposure for three species of Manila clam Ruditapes philippinarum by NMR-based metabolomics. Environ. Toxicol. Phar. 31, 323-332.

Livak, K.J., Schmittgen, T.D., 2001. Analysis of relative gene expression data using real-time quantitative PCR and the $2^{-\Delta \Delta C_{\mathrm{T}}}$ method. Methods 25, 402-408.

Mingeotleclercq, M.P., Brasseur, R., Schanck, A., 1995. Molecular-parameters involved in aminoglycoside nephrotoxicity. J. Toxicol. Env. Health 44, 263-300.

Oliveira, P.F., Alves, M.G., Rato, L., Silva, J., Sa, R., Barros, A., Sousa, M., Carvalho, R.A., Cavaco, J.E., Socorro, S., 2011. Influence of $5 \alpha$-dihydrotestosterone and $17 \beta$ estradiol on human Sertoli cells metabolism. Int. J. Androl. 34, E612-E620.

Pan, X., Tang, J., Li, J., Guo, Z., Zhang, G., 2010. Levels and distributions of PBDEs and PCBs in sediments of the Bohai Sea, North China. J. Environ. Monitor. 12, 12341241.

Parsons, H.M., Ludwig, C., Gunther, U.L., Viant, M.R., 2007. Improved classification accuracy in 1-and 2-dimensional NMR metabolomics data using the variance stabilising generalised logarithm transformation. Bmc Bioinform. 8, 234.

Pellacani, C., Buschini, A., Galati, S., Mussi, F., Franzoni, S., Costa, L.G., 2012. Evaluation of DNA damage induced by 2 polybrominated diphenyl ether flame retardants (BDE-47 and BDE-209) in SK-N-MC cells. Int. J. Toxicol. 31, 372-379.

Petros, A.M., Olejniczak, E.T., Fesik, S.W., 2004. Structural biology of the Bcl-2 family of proteins. BBA-Mol. Cell Res. 1644, 83-94.

Rademacher, T., Parekh, R., Dwek, R., 1988. Glycobiology. Annu. Rev. Biochem. 57, $785-838$.

Rato, L., Alves, M.G., Socorro, S., Carvalho, R.A., Cavaco, J.E., Oliveira, P.F., 2012 Metabolic modulation induced by oestradiol and DHT in immature rat Sertoli cells cultured in vitro. Biosci. Rep. 32, 61-69.

Schecter, A., Johnson-Welch, S., Tung, K.C., Harris, T.R., Papke, O., Rosen, R., 2007 Polybrominated diphenyl ether (PBDE) levels in livers of US human fetuses and newborns. J. Toxicol. Env. Heal. A 70, 1-6.

Shao, J., White, C.C., Dabrowski, M.J., Kavanagh, T.J., Eckert, M.L., Gallagher, E.P., 2008. The role of mitochondrial and oxidative injury in BDE 47 toxicity to human fetal liver hematopoietic stem cells. Toxicol. Sci. 101, 81-90.

Song, R.F., Duarte, T.L., Almeida, G.M., Farmer, P.B., Cooke, M.S., Zhang, W., Sheng, G., Fu, J., Jones, G.D.D., 2009. Cytotoxicity and gene expression profiling of two hydroxylated polybrominated diphenyl ethers in human H295R adrenocortical carcinoma cells. Toxicol. Lett. 185, 23-31.

Tagliaferri, S., Caglieri, A., Goldoni, M., Pinelli, S., Alinnovi, R., Poli, D., Pellacani, C., Giordano, G., Mutti, A., Costa, L.G., 2010. Low concentrations of the brominated flame retardants BDE-47 and BDE-99 induce synergistic oxidative stressmediated neurotoxicity in human neuroblastoma cells. Toxicol. in Vitro 24, $116-122$.

U.S. EPA, 2010. An Exposure Assessment of Polybrominated Diphenyl Ethers (PBDE) (Final). U.S. Environmental Protection Agency, Washington, DC, pp. 378.

Wan, Y., Hu, J., Zhang, K., An, L., 2008. Trophodynamics of polybrominated diphenyl ethers in the marine food web of Bohai Bay, North China. Environ. Sci. Technol. 42, 1078-1083.

Wang, L., Zou, W., Zhong, Y., An, J., Zhang, X., Wu, M., Yu, Z., 2012. The hormesis effect of BDE-47 in $\mathrm{HepG}_{2}$ cells and the potential molecular mechanism. Toxicol. Lett. 209, 193-201.

Williams, T.D., Turan, N., Diab, A.M., Wu, H., Mackenzie, C., Bartie, K.L., Hrydziuszko, O., Lyons, B.P., Stentiford, G.D., Herbert, J.M., Abraham, J.K., Katsiadaki, I., Leaver, M.J., Taggart, J.B., George, S.G., Viant, M.R., Chipman, K.J., Falciani, F., 2011 Towards a system level understanding of non-model organisms sampled from the environment: a network biology approach. PloS Comput. Biol. 7, e1002126. 
Wu, H., Li, X., Feng, J., Li, W., Li, Z., Liao, P., Wu, Y., Pei, F., 2006. Comparison of biochemical effects induced by Changle between male and female rats using NMR and ICP-MS techniques. J. Rare Earth. 24, 108-114.

Wu, H., Southam, A.D., Hines, A., Viant, M.R., 2008. High-throughput tissue extraction protocol for NMR- and MS-based metabolomics. Anal. Biochem. 372, 204-212.

Wu, H., Liu, X., Zhang, X., Ji, C., Zhao, J., Yu, J., 2013. Proteomic and metabolomic responses of clam Ruditapes philippinarum to arsenic exposure under different salinities. Aquat. Toxicol. 136, 91-100.

Xu, L., 2004. Methods of Chemometrics. Science Press, Beijing. pp 221-227.

Yan, C., Huang, D., Zhang, Y., 2011. The involvement of ROS overproduction and mitochondrial dysfunction in PBDE-47-induced apoptosis on Jurkat cells. Exp. Toxicol. Pathol. 63, 413-417.

Yang, E., Zha, J., Jockel, J., Boise, L.H., Thompson, C.B., Korsmeyer, S.J., 1995. Bad, a heterodimeric partner for $\mathrm{Bcl}-\mathrm{X}_{\mathrm{L}}$ and $\mathrm{Bcl}-2$, displaces Bax and promotes celldeath. Cell 80, 285-291.
Yogui, G.T., Sericano, J.L., 2009. Polybrominated diphenyl ether flame retardants in the US marine environment: a review. Environ. Int. 35, 655-666.

Zhang, L., Liu, X., You, L., Zhou, D., Wang, Q., Li, F., Cong, M., Li, L., Zhao, J., Liu, D., Yu, J., Wu, H., 2011a. Benzo(a)pyrene-induced metabolic responses in Manila clam Ruditapes philippinarum by proton nuclear magnetic resonance ( ${ }^{1} \mathrm{H}$ NMR) based metabolomics. Environ. Toxicol. Phar. 32, 218-225.

Zhang, L., Liu, X., You, L., Zhou, D., Wu, H., Li, L., Zhao, J., Feng, J., Yu, J., 2011b. Metabolic responses in gills of Manila clam Ruditapes philippinarum exposed to copper using NMR-based metabolomics. Mar. Environ. Res. 72, 33-39.

Zhong, Y., Wang, L., Yin, L., An, J., Hou, M., Zheng, K., Zhang, X., Wu, M., Yu, Z., Sheng, G., Fu, J., 2011. Cytotoxic effects and oxidative stress response of six PBDE metabolites on human L02 cells. J. Environ. Sci. Heal. A 46, 13201327.

Zorov, D.B., Juhaszova, M., Sollott, S.J., 2006. Mitochondrial ROS-induced ROS release: an update and review. BBA-Bioenergetics 1757, 509-517. 